\title{
EDITORIAL
}

\section{Social science and the complexity of tropical medicine}

\author{
David Gaus [1] \\ 1. Andean Health and Develoment
}

Doi: https://doi.org/10.23936/pfr.v5i2.160

PRÁCTICA FAMILIAR RURAL | Vol.5 | No.2 | Julio 2020 | Received: 20/07/2020 | Approved: 24/07/2020

\author{
Cómo citar este artículo \\ Gaus, D. Social science and the complexity of tropical medicine. Práctica Familiar \\ Rural. 2020 julio; 5(2).
}

\section{Share

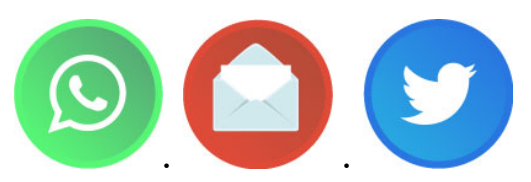

\section{Tropical medicine is at a crossroads}

In the name of biomedicine, humankind has witnessed incredible advances in causative agents, life cycles, treatment, and prevention of many population-crushing parasitic, bacterial, and viral infections such as Malaria, Typhoid, and Yellow Fever. Originally designed to protect imperial troops in tropical climates from maladies previously unknown in the fatherland, the now anachronistic term "tropical medicine" attempts to capture the interplay of local culture, poverty, and the environment - areas where biomedicine encounters major limitations. The existence of the thirteen "Neglected Tropical Diseases" (NTDs) responsible for disabling conditions that mostly affect the world's poorest populations, are a testament to the shortcomings of biomedically-driven tropical medicine.

Some would argue that augmented social science research in tropical medicine is the answer, but the facts do not necessarily bear this out. From 1998-2008 the Gates foundation funded 67 projects of which 26 (39\%) were social science related(1). That said, greater research in social science is required to inform the biomedical model of tropical medicine. One study demonstrated that of the $\$ 2.5$ billion invested in research 
and development of NTD products, $80 \%$ went to HIV, tuberculosis, and malaria, with a heavy focus on drugs and vaccines(2). In fact, the participation of social sciences in tropical medicine, and in development in general, has evolved considerably over the past several decades.

Anthropologist James Ferguson's The Anti-Politics Machine (1990) argues that the international aid industry de-politicizes social realities as a way of asserting control over them, effectively ignoring local social context(ㄱ). Power dynamics of development permit the disengagement from actual local context, allowing for proposed technical solutions to be applied with international expertise, free of local context. This results in ineffective approaches and perpetuates structural inequalities. Foucault's The Birth of the Clinic (1973) influenced Ferguson, arguing that the medical encounter removes the human body from the social context and turns it into an object for technical investigation( $(\underline{4})$.

Since that paradigmatic work, others have argued that Ferguson ignores the complexities of international organizations and local governments, and how soft funding is managed(므). Significant discrepancies exist between the content of formal reports and "divergent points of view that they encode"(므). This cognitive dissonance is reinforced through beliefs in universal codes such as socially hegemonic ideas about human rights, poverty, economic liberalism, and biomedicine. The strongest of these is likely biomedicine with its almost unquestionable body of knowledge that legitimizes health-related development programs, insulating researchers from critical scrutiny.(7). Threatened funding sources supporting international agencies and local officials resulting from negative findings of treatment programs can also feed this cognitive dissonance. As one health official in Tanzania reflected on the difficulties of dissenting opinions, "We are the black guys with no money, and they are the white guys with lots of money"(ㄱ).

Mass drug administration remains a fundamental component to tropical medicine, frequently implemented through vertical disease programs. Social scientists, having exposed the shortfalls in how success is reported, question the initial apparent success of these programs. For example, merely reporting the number of tablets that pass through the healthcare system does not necessarily reflect if they were actually delivered to patients and consumed(ㄱ). Fear of treatment is also under-reported. There is also a tendency to assume that smaller, selected sentinel studies showing changing infection rates are being extrapolated to the wider population.(). Pokhrel (2011) concludes that, in spite of "compelling... cost effective drugs and technologies to treat NTDs, little effort appears to be going into... enhanced delivery of these technologies to target populations"(ㅁ).

Tropical medicine as a discipline continues to develop impactful drugs and technologies now available for an ever-expanding global population. This must continue. However, greater sophistication is required in the understanding of how best to introduce these drugs and technologies within local contexts and in the measurement of their impact. Current antagonistic and controversial relationships between the social sciences and those of the hegemonic biomedical model could inform that sophistication.

\section{Bibliographic references}

1. Pokhrel S, Reidpath D, Allotey P. Social sciences research in neglected tropical diseases 3: investment in social science research in neglected diseases of poverty: a case study of Bill and Melinda Gates Foundation. Health Res Policy Syst. 2011;9:2 doi: 10.1186/1478-4505-9-2

2. Moran M, Guzman J, Ropars A, McDonald A, Jameson N, Omune B. et al.Neglected Disease Research and Development: How Much Are We Really Spending? PLoS Med. 2009;6(2):e1000030. doi: 10.1371/journal.pmed.1000030.

3. Ferguson J. The anti-politics machine: 'Development,' Depolitization and Bureaucratic Power in Lesotho. 1990. Cambridge, UK: Cambridge University Press. 
4. Foucault M. The birth of the clinic: an archeology of medical perception. London: Tavistock Publications Limited.

5. Parker M, Allen T. De-Politicizing Parasites: Reflections on Attempts to Control the Control of Neglected Tropical Diseases, Medical Anthropology, (2014) 33:3, 223-239, DOI: $10.1080 / 01459740.2013 .831414$

6. Mosse D. Cultivating development: an ethnography of aid policy and practice. (2005)London: Pluto Press

7. Parker M, Allen T. Does mass drug administration for the integrated treatment of neglected tropical diseases really work? Assessing evidence for the control of schistosomiasis and soil-transmitted helminths in Uganda. 2011. Health Research Policy and Systems 9:3

8. Parker M, Allen T. Will mass drug administration eliminate lymphatic filariasis? evidence from northern coastal Tanzania. 2013. Journal of Biosocial Science 45:517-545.

9. Pokhrel S, et al. (2011) 